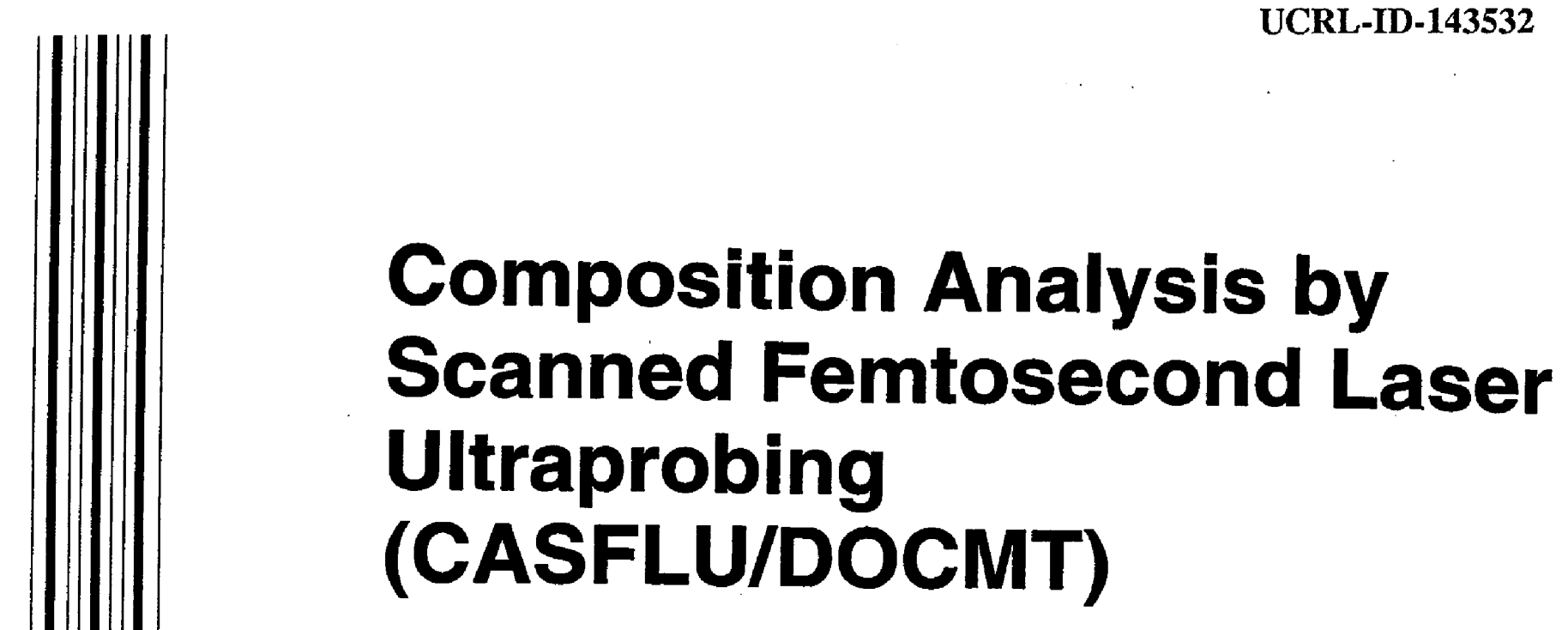

\title{
LDRD Final Report
} 00-ERD-068

M. Y. Ishikawa, J. P. Armstrong, B. C. Stuart, L. L. Wood and A. E. Wynne

February 26, 2001

\section{U.S. Department of Energy}

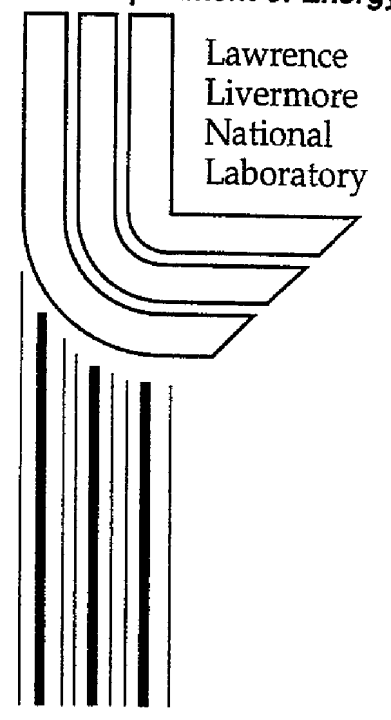




\section{DISCLAIMER}

This document was prepared as an account of work sponsored by an agency of the United States Government. Neither the United States Government nor the University of California nor any of their employees, makes any warranty, express or implied, or assumes any legal liability or responsibility for the accuracy, completeness, or usefulness of any information, apparatus, product, or process disclosed, or represents that its use would not infringe privately owned rights. Reference herein to any specific commercial product, process, or service by trade name, trademark, manufacturer, or otherwise, does not necessarily constitute or imply its endorsement, recommendation, or favoring by the United States Government or the University of California. The views and opinions of authors expressed herein do not necessarily state or reflect those of the United States Government or the University of California, and shall not be used for advertising or product endorsement purposes.

This work was performed under the auspices of the U.S. Department of Energy by the University of California, Lawrence Livermore National Laboratory under Contract No. W-7405-Eng-48.

This report has been reproduced directly from the best available copy.

Available to DOE and DOE contractors from the Office of Scientific and Technical Information P.O. Box 62, Oak Ridge, TN 37831

Prices available from (423) 576-8401 http://apollo.osti.gov/bridge/

Available to the public from the National Technical Information Service

U.S. Department of Commerce 5285 Port Royal Rd., Springfield, VA 22161

http://www.ntis.gov/

OR

Lawrence Livermore National Laboratory Technical Information Department's Digital Library http://www.llnl.gov/tid/Library.html 


\section{High-Speed, Three-Dimensional Object Composition Mapping Technology}

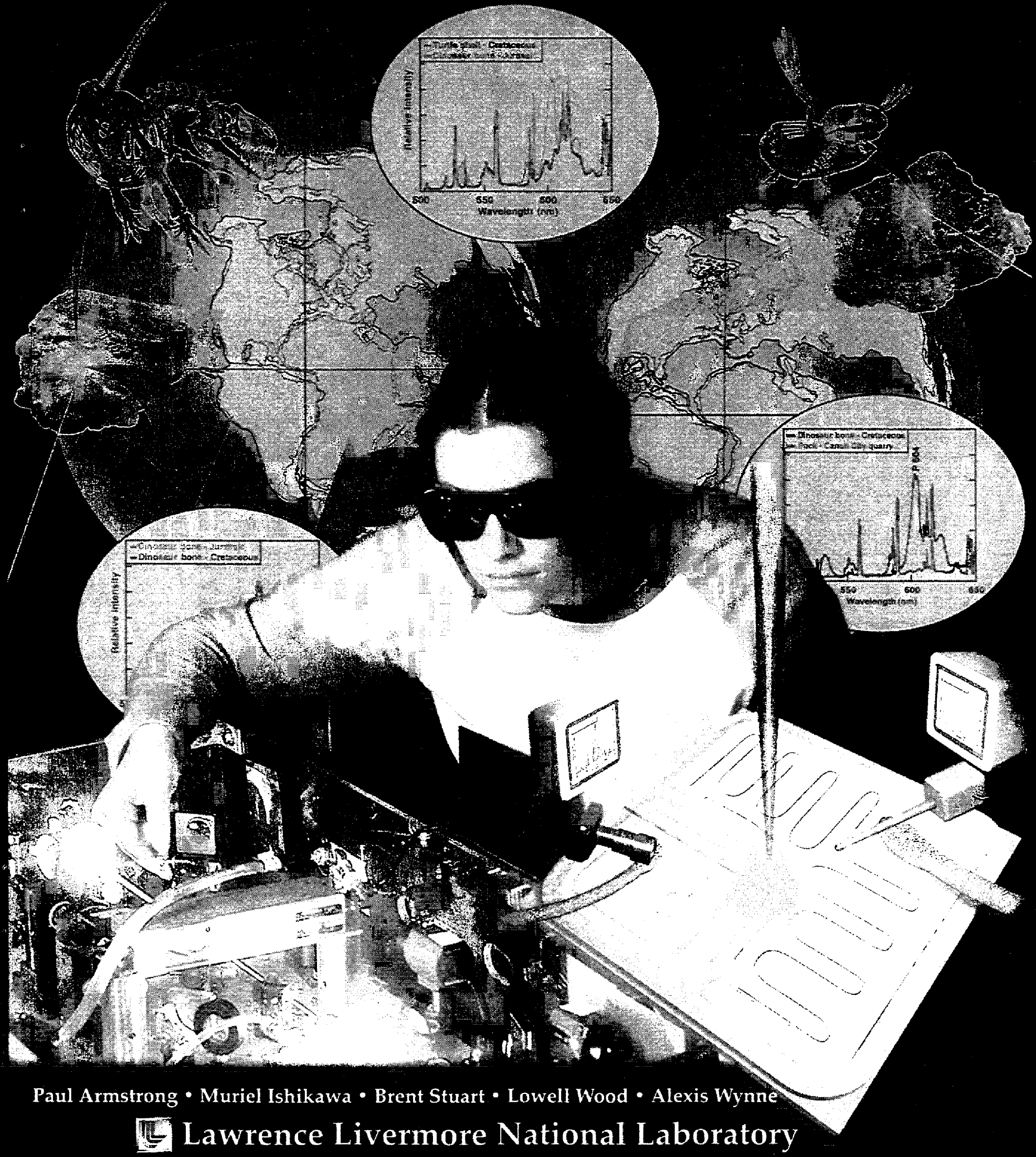




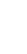




\title{
COMPOSITION ANALYSIS BY SCANNED FEMTOSECOND LASER ULTRAPROBING (CASFLU/DOCMT) Final Report 00-ERD-068
}

\author{
Muriel Y. Ishikawa, Paul Armstrong, Brent Stuart, \\ Lowell Wood and Alexis Wynne \\ Lawrence Livermore National Laboratory \\ Livermore, California
}

\begin{abstract}
${ }^{1}$
A new technology for ultrahigh-spatial resolution mapping of the isotopic, molecular, and chemical compositions of complex, multi-dimensional objects, in semiconductor, archaeological, paleontological, biological and materials R\&D.
\end{abstract}

INTRODUCTION. This document overviews an entirely new approach to determining the composition - the chemical-elemental, isotopic and molecular make-up - of complex, highly structured objects, moreover with microscopic spatial resolution in all 3 dimensions.

The front cover depicts the new type of pulsed laser system, at the heart of this novel technology, under adjustment by Alexis Wynne, and schematically indicates two of its early uses: swiftly analyzing the 3-D composition governed structure of a transistor circuit with both optical and mass-spectrometric detectors, and of fossilized dinosaur and turtle bones high-speed probed by optical detection means.

Studying the composition-cued, 3-D micro-structures of advanced composite materials and the microscopic scale composition-texture of biological tissues are two near-term examples of the rich spectrum of novel applications enabled by this analytic tool-set.

DISCUSSION. CASFLU was an original concept that was funded by LDRD in FY2000. The proposed CASFLU goals were met early enough in FY2000 that other major improvements were incorporated. These included full automation of 3-D analytic capabilities: simultaneous multi-element analysis and compositionmapping; computerized semi-automatic generation of material composition maps; and demonstration of full-scale semiconductor device dissection and composition-mapping which is of immediate interest to the advanced

1 This work was performed under the auspices of the U.S. Department of Energy by the University of California Lawrence Livermore National Laboratory under contract No. W-7405-ENG-48. 
semiconductor R\&D and manufacturing communities. These advances greatly extended the demonstrated domain-of-capabilities of the present technology and thereby increased substantially technological attractiveness to potential customer communities. As a result, the CASFLU acronym was subsequently changed to DOCMT, for High-Speed, Three-Dimensional Object Composition Mapping Technology.

What does it do? CASFLU/DOCMT is a fully automated, high-speed technology useful for mapping the spatially-varying material composition of an object. It can be used for the chemical, molecular and isotopic composition analysis of complex, three-dimensional objects of any nature, and its spatial resolution is at the microscopic (potentially sub-micrometer) level.

This composition mapping technology integrates a femtosecond laser, an optical and/or mass spectrometer, and a control computer into a powerful tool used to determine the material make-up of objects of all types, shapes, and compositions. Near-term applications are in the semiconductor industry, in materials, medical, paleontological and archaeological research, and in national security task-areas.

How does it do it? Because the laser pulses used are extremely short in duration ( $\leq 100$ femtoseconds, or $10^{-13}$ seconds), they can remove a very thin (submicrometer) surface layer of an object without heating or shocking underlying material - the object's uppermost layer is heated to $>10,000$ kelvins in a tenth of a trillionth of a second. The superheated, completely gasified material 'gently' lifts off on a sub-nanosecond time scale. What remains is an unheated, unshocked, flat surface that looks precisely micro-machined, and is suitable for subsequent analysis.

Composition analysis. The tiny parcel of material ablated by each focused laser beam pulse may be analyzed in real time by spectrometers for chemical, isotopic, and molecular compositions; the entire object is analyzed by sweeping trains of these pulses across the object's exposed surface, repetitively. (The object surface being analyzed is typically shrouded by flowing inert gas; the mass spectrometer's inlet sees only the inert gas except when exposed to the vapor from the pulse-ablated material, which is uncontaminated with vapor-air reaction products). The chemical composition of ablated material is determined by optical spectrometry, which examines the electronic spectral signature briefly emitted by each tiny parcel of the vaporized material. This sampling-analysis cycle may be made to occur millions of times per second, and may be repeated indefinitely, under computer control. The entire surface of the object being analyzed is precision-scanned under the focal spot of the laser beam to generate a two-dimensional composition map of its presented surface. This twodimensional analysis is iterated, layer-by-layer, to build up a microscopically precise three-dimensional map of the object's composition. 
What theories, if any, are involved? The energy of pulsed laser irradiation is absorbed by the electrons in the topmost layers of a material and is thermally conducted by them and subsequently by the material's intermingled atoms and ions, as the hot electrons couple thermal energy into them. For laser pulses of durations that are short compared to the material's electron-ion thermal coupling time (about 1 picosecond), the very high pressure of the superheated electron 'gas' by itself causes the associated 'cold' material to explosively lift off in a layer that is only a few electron scattering-lengths in depth. Since the $>99.9 \%$ of the mass of the vaporized material represented in atoms and ions never gets hot, the underlying surface isn't significantly heated or otherwise damaged. This phenomenon is necessarily limited to femtosecond-pulse irradiation and results in a novel type of material machining offered by the very high spatial resolution of focused laser light.

COMPARISON TO OTHER TECHNOLOGIES. There are no known technologies in the general performance class of this technology. All previous composition-mapping technologies are severely limited by their spatial resolution, composition range, or size or shape of analyzable objects. The comparative performance shortfalls are qualitative ones. Nothing else can microdissect an object of arbitrary composition in 2- or 3-D, and composition-analyze the dissected mass-packets with any significant generality of chemical and/or isotopic composition or high speed or automation, moreover in a 'seamless' manner.

A unique application of the High-Speed 3-D Object Composition Mapping Technology derives from its ability to determine an object's local composition in real time. Leveraging this capability, systems expressing this technology can extract (potentially microscopic) "daughter" objects embedded within a "parent" object. The system's laser can suspend ablation on low-latency time scales when the control computer detects either a pre-designated or unknown material via interpretation of signals from a detector head, while continuing to swiftly ablate micro-parcels more distantly from this 'preferred' material. The embedded or "daughter" object can thereby be rapidly and automatically 'carved out' of its surrounding matrix, moreover with microscopic precision. There is no known technology that can perform such extractions with any generality. This capability is of particular interest to the paleontological and archaeological communities, as well as to the biological micro-anatomy one.

On the following pages, we provide a detailed breakdown of technological improvements. 


\section{KEY FEATURES OF CASFLU/DOCMT IN COMPARISON TO OTHER COMPETITIVE TECHNOLOGIES.}

The present technology broadly and directly benefits the overall hightechnology sectors of the economy by providing a first-of-its-kind tool for automatically and precisely disassembling and composition-analyzing complex, three-dimensional objects and doing so at very high speed and without human contact with the objects as they're being analyzed.

The ability to "look" at objects on single-micrometer spatial scales is comparable to that of the best optical microscopes (which, indeed, are employed to focus the ultra-short pulses of laser light). However, the ability to thereupon analyze the molecular, chemical-elemental and isotopic compositions of the volumes examined on these same microscopic resolution scales, all over an area which is potentially dozens to hundreds of square centimeters in extent, is completely unprecedented - and is of great significance to advanced understanding of both the micro-structure and the utility of materials of all types.

The ability to then "push" the surface being so examined all the way through the entire object in fractional micrometer steps - while maintaining microscopic spatial resolution in the two transverse dimensions - is also quite novel, and can be expected to lead to greatly improved understanding of many aspects of

advanced and highly-structured materials, e.g., high-strength composites and 3D composition and connectivity of biological tissues.

In the following two tables, the CASFLU/DOCMT technology is systematically compared to other existing competing technologies in terms of implementation, applicability, and other pertinent aspects. 
Technologies

\begin{tabular}{|c|c|c|c|c|}
\hline Characteristics & $\begin{array}{l}\text { X-Pay } \\
\text { Tomography }\end{array}$ & $\begin{array}{l}\text { Magnetic } \\
\text { Resonance } \\
\text { Imaging }\end{array}$ & $\begin{array}{l}\text { Stacks-of-Planar } \\
\text { Slabs Analysis }\end{array}$ & DOCMT \\
\hline Implementation & $\begin{array}{l}\text { "CAT scan" } \\
\text { imagery }\end{array}$ & MRl imagery & $\begin{array}{l}\text { Microtome-to- } \\
\text { slide-to-optical } \\
\text { microscope } \\
\text { imaging }\end{array}$ & $\begin{array}{l}\text { Scanned- } \\
\text { dissection } \\
\text { whole-object } \\
\text { analysis }\end{array}$ \\
\hline $\begin{array}{l}\text { Spatial } \\
\text { resolution: } \\
\text { Transverse Depth }\end{array}$ & $\begin{array}{l}\sim 0.05 \mathrm{~cm} \\
\sim 0.05 \mathrm{~cm}\end{array}$ & $\begin{array}{l}-0.05 \mathrm{~cm} \\
-0.1 \mathrm{~cm}\end{array}$ & $\begin{array}{l}-0.0001 \mathrm{~cm} \\
\sim 0.001 \mathrm{~cm}\end{array}$ & $\begin{array}{l}-0.0001 \mathrm{~cm} \\
\sim 0.00001 \mathrm{~cm}\end{array}$ \\
\hline $\begin{array}{l}\text { Chemical-element } \\
\text { resolution }\end{array}$ & $\begin{array}{l}\text { Crude; } \\
\text { specialized }\end{array}$ & $\begin{array}{l}\text { Nearly non- } \\
\text { existent }\end{array}$ & $\begin{array}{l}\text { Elemental stains } \\
\text { only }\end{array}$ & All elements \\
\hline $\begin{array}{l}\text { Isotopic resolution } \\
\text { capabilities }\end{array}$ & None & Very few & None & All isotopes \\
\hline $\begin{array}{l}\text { Molecular } \\
\text { identification } \\
\text { capabilities }\end{array}$ & None & $\begin{array}{l}\text { Contrast } \\
\text { agents only }\end{array}$ & $\begin{array}{l}\text { Stained entities } \\
\text { only }\end{array}$ & $\begin{array}{l}\text { Full mass- } \\
\text { spectrometer } \\
\text { capabilities }\end{array}$ \\
\hline Cost & High & High & Low & Moderate \\
\hline Applicability & $\begin{array}{l}\text { Low-z or } \\
\text { small objects } \\
\text { only }\end{array}$ & $\begin{array}{l}\text { Non-magnetic, } \\
\text { RF-transparent } \\
\text { objects only }\end{array}$ & $\begin{array}{l}\text { Thin sectioning- } \\
\text { tolerant, optically } \\
\text { transparent }\end{array}$ & $\begin{array}{l}\text { All materials } \\
\text { and all object- } \\
\text { sizes }\end{array}$ \\
\hline
\end{tabular}

The above table compares generally competitive technologies versus implementation; spatial resolution, chemical, isotopic and molecular identification capabilities; and cost and applicability.

\section{COMPARATIVE APPLICABILITY OF EXISTING COMPETITIVE TECHNOLOGIES AND CASFLU/DOCMT.}

This second table displays the comparative applicability of existing analytic technologies in terms of applications to semiconductor device failure analysis, mechanical wear and failure analysis, object construction and biological tissue assay. 
Comparative Applicability of Analytic Technologies

\begin{tabular}{|c|c|c|c|c|}
\hline $\begin{array}{l}\text { Representative } \\
\text { Applications } \\
\text { Classes }\end{array}$ & $\begin{array}{l}\text { X-Ray } \\
\text { Tomographic } \\
\text { (CAT-Scan) } \\
\text { Imaging }\end{array}$ & $\begin{array}{l}\text { Magnetic } \\
\text { Resonance } \\
\text { Imaging }\end{array}$ & $\begin{array}{l}\text { Microtome- } \\
\text { Optical } \\
\text { Microscope } \\
\text { Imaging }\end{array}$ & DOCMT \\
\hline $\begin{array}{l}\text { Semiconductor } \\
\text { device failure } \\
\text { analysis }\end{array}$ & $\begin{array}{l}\text { None tvery } \\
\text { poor resolution: } \\
\text { no chem.) }\end{array}$ & $\begin{array}{l}\text { None (very poor } \\
\text { resolution: ho } \\
\text { chem.) }\end{array}$ & $\begin{array}{l}\text { Minimal (inadequate } \\
\text { resolution: limited } \\
\text { chem.: no penetration) }\end{array}$ & Full \\
\hline $\begin{array}{l}\text { Mechanism } \\
\text { wear/failure } \\
\text { analysis }\end{array}$ & $\begin{array}{l}\text { None ipoor } \\
\text { resolution: limited } \\
\text { penetration: }\end{array}$ & $\begin{array}{l}\text { None ipoor } \\
\text { resolution: very } \\
\text { limited penetraion) }\end{array}$ & $\begin{array}{l}\text { None (very limited } \\
\text { penetration: limited } \\
\text { chem. molecular) }\end{array}$ & Full \\
\hline $\begin{array}{l}\text { Object } \\
\text { construction } \\
\text { analysis }\end{array}$ & $\begin{array}{l}\text { Minimal poor } \\
\text { resolution: no } \\
\text { chem. molecular" } \\
\text { penetration. }\end{array}$ & $\begin{array}{l}\text { None ipoor } \\
\text { resolution: no } \\
\text { chem, molecular: } \\
\text { very limied } \\
\text { penetration! }\end{array}$ & $\begin{array}{l}\text { None (very limited } \\
\text { penetration: limited } \\
\text { chem. molecular) }\end{array}$ & Full \\
\hline $\begin{array}{l}\text { Biological tissue } \\
\text { analysis }\end{array}$ & $\begin{array}{l}\text { Minimal (poor } \\
\text { resolution: no } \\
\text { chentical or } \\
\text { molecular) }\end{array}$ & $\begin{array}{l}\text { Minimal poor } \\
\text { resolution: very } \\
\text { limited chemical of } \\
\text { molecular) }\end{array}$ & $\begin{array}{l}\text { Marginal (limited } \\
\text { penetration; very } \\
\text { limited/stylized } \\
\text { chem_/molecular \& no } \\
\text { isotopic) }\end{array}$ & Full \\
\hline
\end{tabular}

TECHNOLOGICAL IMPROVEMENTS. On the following pages, we provide a detailed breakdown of CASFLU/DOCMT technological improvements.

\section{Spatial Resolution.}

- Optical microscopy has comparable transverse spatial resolution, but

- it has exceedingly limited depth resolution, and only over very small total transverse field-sizes and depths-of-field.

- it has essentially no ability to analyze chemical or isotopic composition, and its molecular composition analysis is limited to a handful of stains and fluors.

- Potentially 3-D analysis systems such as MRI and x-ray tomography

- have at least a hundred-fold poorer limiting spatial resolutions in all three dimensions (i.e., a typical minimum feature-size is $>>100$ micrometers).

- are very limited in the range of chemical and isotopic compositions they can assay. In general, they report appearance but not composition, form but not content. 


\section{Composition Range and Type.}

The present technology has all-materials analytic capabilities. In comparison,

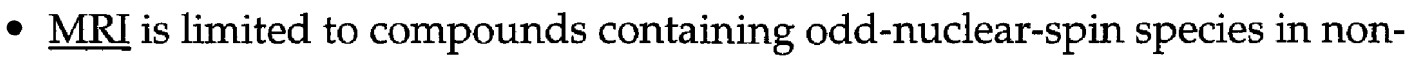
magnetic materials.

- $\underline{X}$-ray tomographic approaches (e.g, CAT-scan) must work with only single-element line-edges in nearly ( $x$-ray) transparent media.

- SIMS techniques offer no significant 2- or 3-D spatial analytic coverage, little unambiguous chemical/molecular information, and isotopic mass resolution of only intermediate quality and reliability.

\section{Material Types.}

The present technology is indifferent to the type of materials being analyzed. In comparison,

- MRI works only with non-magnetic materials and essentially assays for a small number of odd-spin nuclei.

- Specialized CAT-scanning can resolve materials of just a single chemicalelemental composition.

- Optical microscopy is limited to nearly transparent materials and has no intrinsic chemical or isotopic analytic ability. Its molecular composition ability is limited to ad hoc staining with colored, fluorescent, or optically dense materials of negligible generality.

\section{Object Scales.}

- The present technology works with objects of any size or shape. Other composition-mapping technologies are limited to objects that present only a small number of optical depths to the various radiations with which they are probed, e.g., non-metallic objects. This restriction to nearly transparent objects often is severely limiting.

- The present technology uniquely combines the spatial resolution of an optical microscope with the analytic power of simultaneously applied opticaland mass-spectroscopy.

- Moreover, the present technology composition-maps objects at singularly high sampling rates: $\left(10^{8} /\right.$ second, thereby making practical the composition mapping of extended 2- and 3-D objects, and, moreover, with microscopic precision. 


\section{Simultaneous Multi-axis Composition-Mapping.}

The present technology can look simultaneously at the chemical, isotopic, and molecular compositions of an object being analyzed, moreover at very high spatial-tracking rates. All other analytic approaches look at an object only along a single axis in composition-space, and typically do so at exceedingly modest spatial-track speeds.

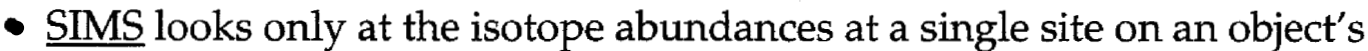
surface with moderate-mass resolution.

- Optical microscopy looks only at the optical density within a thin, semitransparent section of a (possibly fluor- or stain-taking) material, in 2-D.

- Ordinary CAT-scanning looks only at total electron density, while advanced CAT techniques can examine only the density of a single chemical element.

In summary, the present CASFLU/DOCMT technology represents a qualitative advance over the best previously existing technologies for composition-analyzing complex 2- \& 3-D objects.

\section{PRINCIPAL APPLICATIONS OF THIS WORK.}

\section{Benefits to the General Public.}

As a powerful, general-purpose means for understanding the structure of material objects - whether naturally-occurring or man-made - the present technology can be expected to come into widespread use in analytical science and engineering and thus to have large-scale beneficial consequences. Both the direct and indirect benefits to the economy can reasonably be expected to be large and varied.

\section{Applications.}

This technology broadly and directly benefits the overall high-technology sectors of the economy by providing a first-of-its-kind tool for automatically and precisely disassembling and composition-analyzing complex, three-dimensional objects at very high speed, without human contact with the objects as they are being analyzed.

The ability conferred by the present technology to examine objects on singlemicrometer spatial scales is comparable the best optical microscopes. The ability to look all the way through an entire macroscopic object in fractional micrometer steps - while maintaining microscopic spatial resolution in the two transverse dimensions - may lead to greatly improved understanding of advanced and 
highly-structured materials, ranging from high-performance composites to biological tissues (and their medical surrogates).

Salient semiconductor applications are addressed in an accompanying video that may be requested (UCRL-MI-142551). As a generic example of the

CASFLU/DOCMT High-Speed 3-D Object Composition Mapping Technology, a Darlington bipolar transistor circuit implemented in silicon-aluminum technology was laser raster-scanned in horizontal layers. The video shows the resulting multidimensional computer-synthesized reconstruction, which accentuates the minute thickness of the device, relative to its transverse extents; the individual layers are separated only by a few micrometers. A frame from this video is shown in the lower corner on the front cover of this report.

In addition to microelectronics research, this composition mapping technology is expected to be especially useful in archaeological and paleontological applications. It may be used to separate an object of one composition from surrounding material of differing composition(s), for example, for the microscopically precise retrieval of paleontological and archeological objects embedded inside of closely adhering (and very similar-appearing) surrounding material. Because the composition analyses detect changes in the material in real time, the presence of an embedded object can be detected readily, and the dissection of surrounding material thereby may be guided reliably to effect the embedded object's precise removal.

Two possible applications of this high-speed composition-mapping technology are the removal of metal archeological objects from compacted soil or corrosion crusts and the separation of mineralized bone paleontological specimens from surrounding rock.

\section{DISCUSSION OF RESULTS.}

\section{FY1999 Results.}

A first demonstration of the CASFLU capability took place in FY1999 and is illustrated in Figure 1. We have chosen to show this figure in a layout format. 
Figure 1. In 1999, the present technology was successfully employed to differentiate between challenging samples of "rock-in-rock". Cretaceous rock and mineralized bone fossils were compared to each other and to Jurassic rock and fossils from different parts of the U.S. The results are illustrated in this figure. Both fossil bone samples were readily distinguished from rock in which they were embedded and from fossilized contemporaneous chitinous turtle shell, using the optical spectral analytic capabilities of the present technology. In the left plot, two dinosaur fossil bone specimens from different geological times and geographical locations were found to lie on top of each other, in the optical spectral sense. The fossil chitinous turtle shell specimen clearly is differentiated readily from the fossil bone specimen in the center graph. Another plot (omitted for lack of space) showed the two fossil bone-carrying rock specimens also closely related to each other spectrally, despite formation in disparate geologic eras and locations. However, the spectroscopic analysis clearly illuminates the difference spectrally between the fossil bone and the encasing rock in the plot on the right

This research was done in collaboration with Dr. Kenneth Carpenter of the Denver Museum of Natural History in Denver, Colorado and Dr. James Kirkland, State Paleontologist of Utah, Salt Lake City, Utah. [Cf. "Automated, High-Speed, High Resolution Specimen Recovery From Matrix With Femtosecond Laser Pulse-Trains," E.M. Campbell, M. Perry, B. Stuart, M. Ishikawa and L. Wood, J. Vertebrate Paleontology 19, A35 (1999).] 


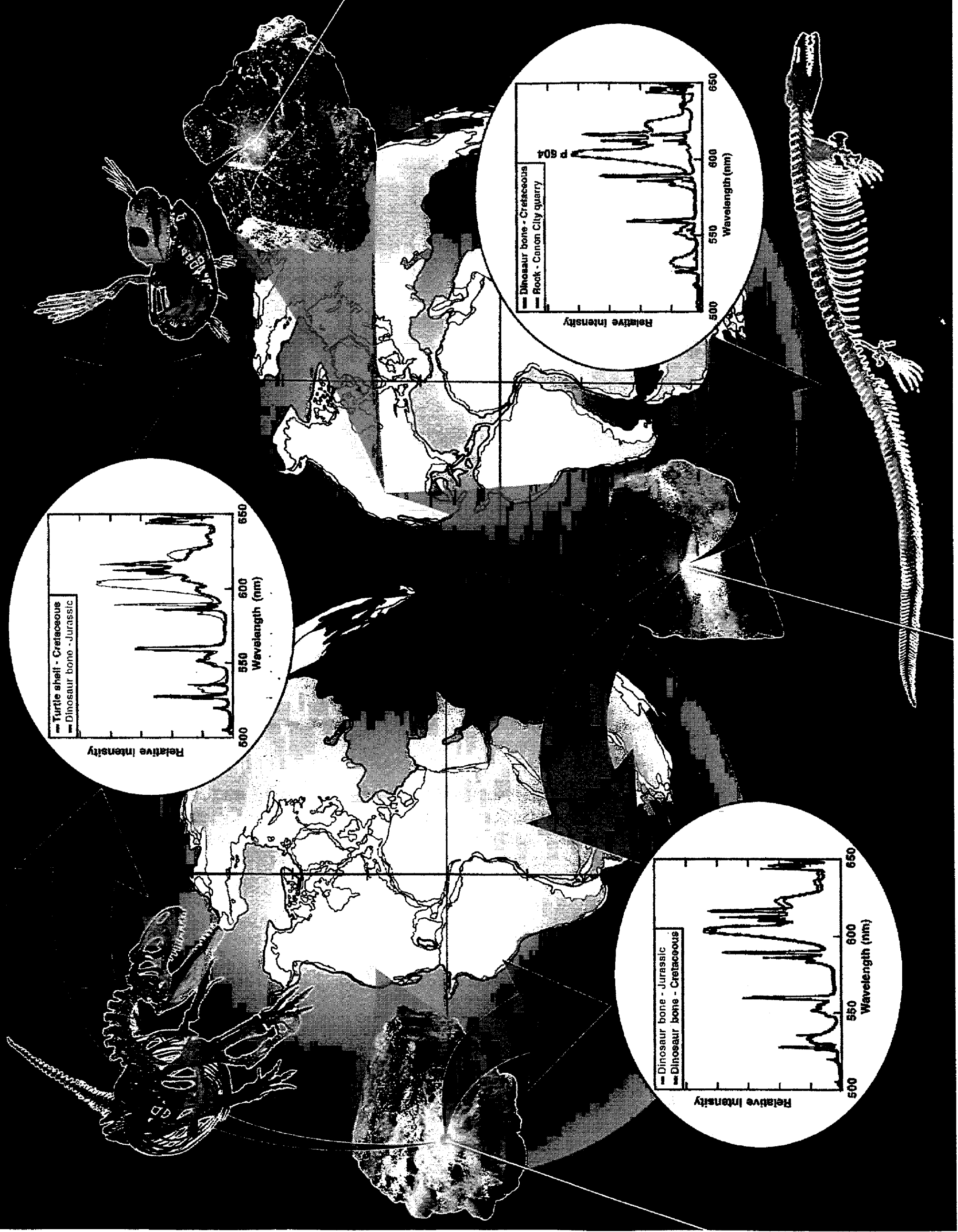



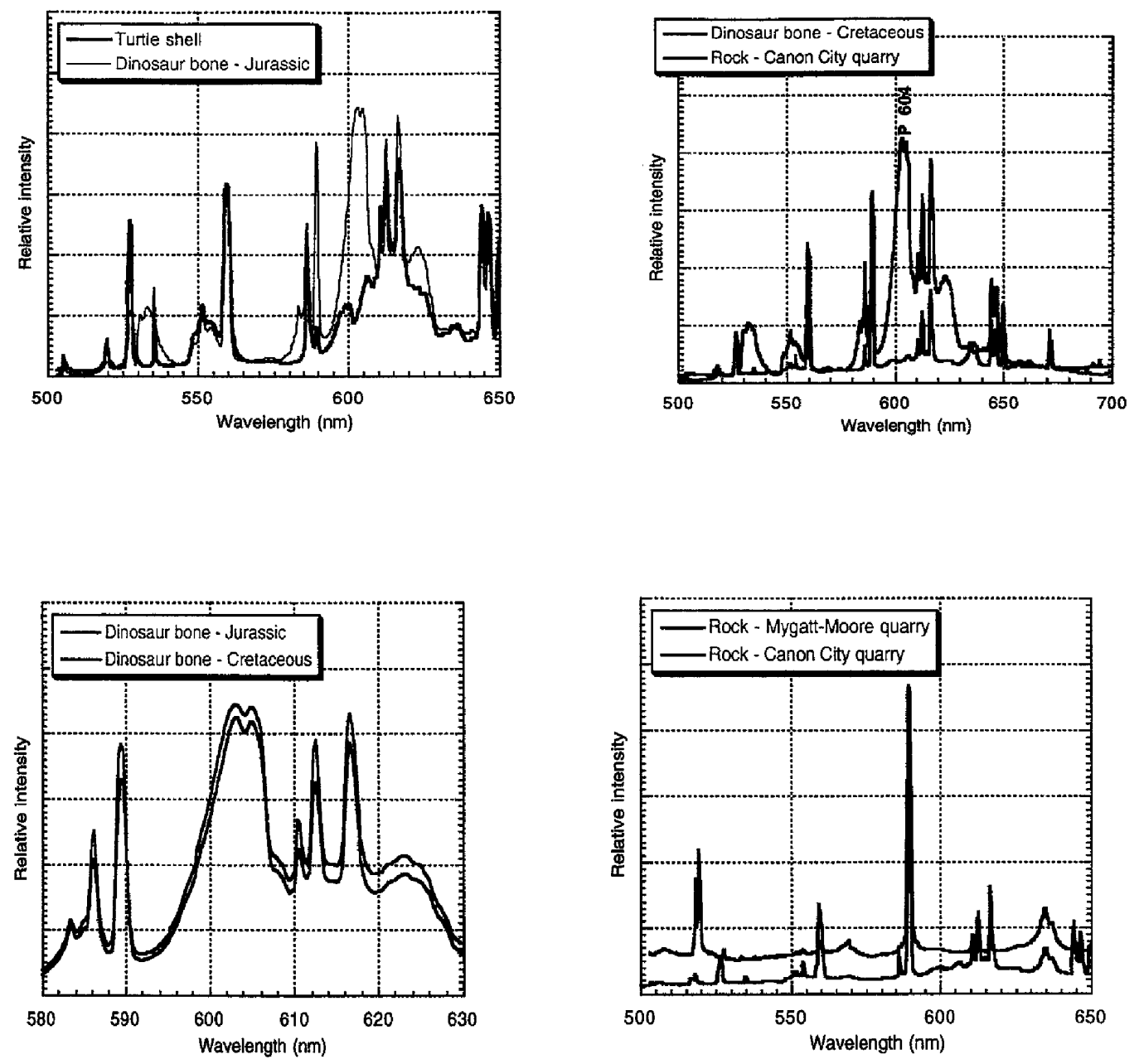

Figure 2. Plots of four major comparisons of fossil bone specimens and rock provided by Kirkland and Carpenter (ref. Figure 1). Note that CASFLU clearly differentiated between fossil bone and rock, as well as fossil chitin and bone, even though all three materials are permineralized. 


\section{FY2000 Results.}

In FY2000, the CASFLU unit was first tested on an industrial-standard, 200 grid, copper mesh test pattern on silicon. CASFLU successfully revealed microscopic warpage present in the test pattern on several micrometer scales. This experiment served to validate CASFLU's laser scanning, analysis and composition mapping capabilities working together and results have been shown in previous publications.

A final, real-world CASFLU/DOCMT proof-of-principal demonstration (also in FY2000) featured the successful dissection, spectroscopic analysis and composition mapping reconstruction of a commercially available silicon Darlington transistor. Real-time analysis of composition data taken during active scanning by a femtosecond laser was reconstructed into a three dimensional map of the object. The composition map clearly revealed aluminum, silicon and aluminum/silicon mixing throughout the object, as well as 3-D features such as grooves and channels. The data was compared to that obtained during scanning electron microscope and x-ray flourescent scans on the top layer of the semiconductor to confirm CASFLU/DOCMT composition data (Figure 3).
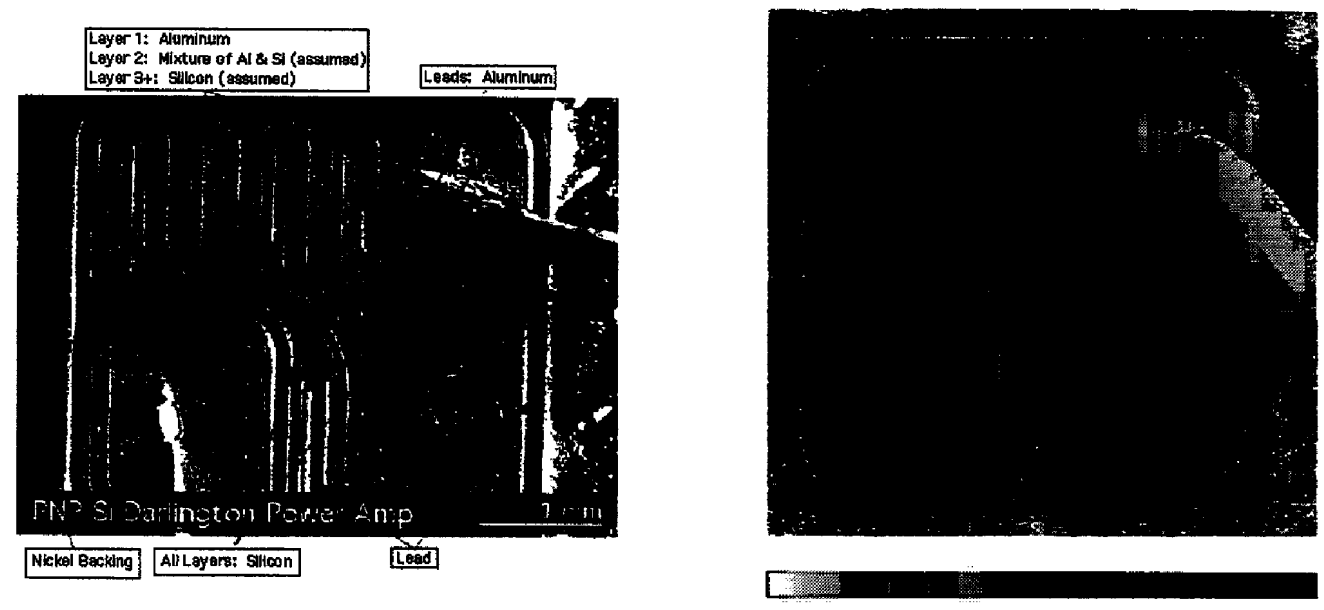

Non-Si sites Si Boundaries $\mathrm{Si}$

Figure 3. The following two figures display a comparison of a high-resolution microscope photograph of a semiconductor which was surface analyzed using SEM and XRF techniques (scale bar corresponding to $1 \mathrm{~mm}$ ) (left) and the top data layer from a CASFL.U/DOCMT 3-D composition map of the same object (right). The contrast between the Si, $\mathrm{Si}$ boundaries and non-Si sites are clearly visible in the resulting analog image. 
CASFLU/DOCMT technology may also be used to compose single element composition maps of 3-D objects as well as multi-element ones. Below we show an example of a 3-D single element composition map reduced from the semiconductor data used to reconstruct Figure 3.

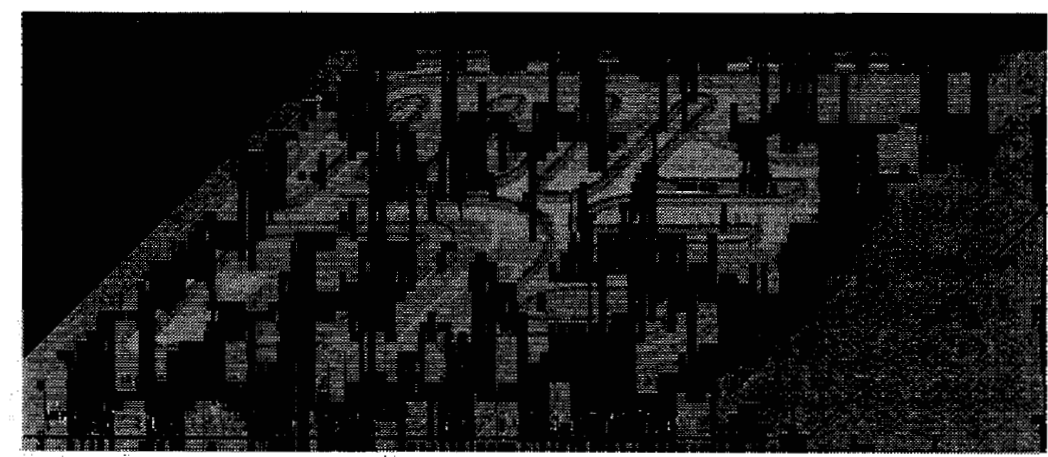

Figure 4. Si-only composition map of the same semiconductor. Note the detailed features inside the object, such as grooves and channels that extend throughout the device. Silicon in this figure has been set to "green".

\section{OTHER APPLICATIONS OF THIS WORK.}

\section{Public Sector Applications.}

The capabilities of the present technology constitute one of the single largest advances in forensic science capabilities during the past half-century: uniformly resolving an object into as many as a trillion uniform mass-parcels or -aliquots per cubic centimeter and reading-out the composition of each such parcel automatically and at very high speed.

For example, both Federal and State law-enforcement agencies can be expected to welcome the capabilities of the present technology for use in the full spectrum of forensic analytic applications. Those agencies of the government charged with responsibilities for reliably and swiftly attributing unconventional and asymmetric attacks on the armed forces, population and interests of the United States likely will also be intrigued by the unique object micro-analysis capabilities being made available by the present technology-set. Other government agencies which have (often, time-urgent) requirements for elucidating the 3-D structure and composition of (typically, small) complex objects likewise may be expected to be pleased by the capabilities of the present technology, e.g., the Environmental Protection Agency may value its ability to differentiate between contested sites-of-origin of fly ash from coal combustion 
via combined chemical and isotopic analyses of single ash particles.

\section{Biological Applications.}

Near-term biological applications center on the elementally guided microdissection of (frozen) biological tissue. Since many tissue-types have very large differences in intra- and extra-cellular concentrations of chemical elements (>1000fold calcium concentration ratios, in the case of mammalian brain tissue), the submicron scale mass aliquoting and composition analyses offered by the present technology may be used to create the first-ever high-resolution, seamless, fullyassembled 3-D maps of all such complex tissue structures, moreover over comparatively very large (e.g., cubic centimeter) volume scales.

The corresponding advances in areas as diverse as fundamental neuroanatomy and tissue engineering are anticipated to be quite large, as all existing microscopic imaging approaches cannot register stacks of 2-D images relative to each other in order generate deep 3-D representations of biological structures. The abilities to "see in depth" and with micrometer-scale resolution in all 3 dimensions which are conferred by the present technology may virtually revolutionize biological microimagery, and may reinvigorate micro-anatomy as a discipline, e.g., entire functional-level neural circuits (with $10^{5}-10^{6}$ neurons) may be imaged in their full interconnectivity for the first time.

\section{Advanced Materials Studies.}

The highest-performance structural materials are composites, usually fiberbased ones. How these materials perform under high loadings, at high temperatures, when abruptly loaded, etc. is often determined by microscopic deviations in compositional properties from the as-built material, e.g., formation of low-density or compositionally-altered microvolumes of complex geometry at-ornear material interfaces within objects comprised of such composites. The present technology will be of exceptional utility in extending understanding of how these unusual materials perform and fail, and thus will point the way to improving them, both in formation and in conditions-of-use. Such prospects are of great interest to a wide variety of modern technologists.

Semiconductor manufacturing and characterization applications have been previously described in this report.

SUMMARY. Optical microscopes extended human vision another two orders of magnitude into the small-scale world, and x-ray imaging enabled human "seeing" into the interiors of apparently opaque objects. Each revolutionized human perceptions of the physical world, and subsequently proved to be of enormous technological significance. 
The CASFLU/DOCMT High Speed 3-D Object Composition-Mapping Technology makes available a major imaging advance, relative to these justlyfamed technology-sets.

Powerfully leveraging and integrating very recent advances in pulsed laser, optical and computing technologies, this novel analytic system provides information on the spatially varying compositions of all types of richly inhomogeneous solid objects - their chemical and isotopic constituents and their molecular natures - automatically and swiftly, moreover with 3-D microscopic resolution and precision over macroscopic scales.

Thus, it represents a fundamental advance in the human ability to better analyze, image and understand - and thus to more aptly utilize and control - the material object-oriented aspects of our physical world. This superior utility and control, expessed over a huge gamut of present-day technology-sets, inevitably will confer great benefits on all mankind, across many fields of endeavor - just as did optical microscopy and $\mathrm{x}$-ray imaging.

Imaging for the first time the $3-D$ chemical-elemental and molecular structures of key biological tissues with micrometer resolution over centimeter distances may constitute the single largest impact of the present technology on either basic science or technology, but will be only one of many.

\section{PUBLICATIONS, PATENTS AND VIDEOS}

1. UCRL-JC-133900, Automated, High-speed, High-Resolution Specimen Recovery from Matrix with Femtosecond Laser Pulse-Trains, Society of Vertebrate Paleontology, Campbell, E. Michael, Perry, Michael, Stuart, Brent, Ishikawa, Muriel and Wood, Lowell.

2. PR-2010, UCRL-MI-137705, CASFLU, Composition Analysis by Scanned Femtosecond Laser Ultraprobing Video, Ishikawa, M. Y., et al.

3. UCRL-MI-137697, Composition Analysis by Scanned Femtosecond Ultraprobing, P. Armstrong, M. Ishikawa, B. Stuart, L. Wood, and A. Wynne.

4. Invention Case: IL-10447, Composition Analysis by Scanned Femtosecond Laser Ultraprobing, Muriel Y. Ishikawa, Lowell L. Wood, E. Michael Campbell, Michael D. Perry, Brent C. Stuart, January 12, 1999.

5. Application for Provisional Patent: IL-10447, CASFLU (Composition Analysis by Scanned Femtosecond Laser Ultraprobing), Muriel Y. Ishikawa et al, May 3, 1999. 
6. Commerce Business Daily, Department of Commerce, U.S.A., Submission No. 464676, Composition Analysis by Scanned Femtosecond Laser Ultraprobing, June 2000.

7. CASFLU, International Application Number: PCT/US00/11911, 2 May 2000. Composition Analysis by Scanning Femtosecond Laser Ultraprobing (CASFLU), International Publication Number: WO 00/67003, International Application published under the Patent Cooperation Treaty (PCT), Ishikawa, Muriel Y. et al, 9 November 2000.

8. U.S. Patent Application, CASFLU, filed 2 May 2000.

9. CASFLU-Composition Analysis by Scanned Femtosecond Laser Ultraprobing, M.Y. Ishikawa, J.P. Armstrong, B.C. Stuart, L.L. Wood, A.E. Wynne, 00-ERD-068, Laboratory Directed Research \& Development FY200) Annual Report.

10. UCRL-ID-142551, High Speed, Three Dimensional Object Composition Mapping Technology, J.P. Armstrong, M.Y. Ishikawa, B.C. Stuart, L.L. Wood and A.E. Wynne, February 14, 2001.

11. UCRL-MI-142551, PR: 002010, DOCMT, High-Speed, 3-Dimensional Object Compostion Mapping Technology, February 14, 2001, Video. 

University of California

Lawrence Livermore National Laboratory

Technical Information Department

Livermore, CA 94551

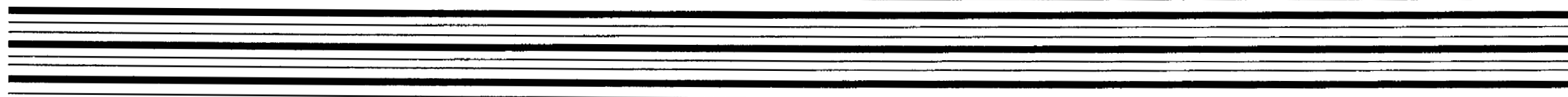

